\title{
Total Thyroidectomy versus Total Thyroidectomy with Prophylactic Central Compartment Neck Dissection in Early Papillary Thyroid Cancer
}

\author{
AYMAN A. ABD-RABHOU, M.D.; HESHAM M.A. OMRAN, M.D.; \\ HOSSAM S. ABDELRAHIM, M.D., M.R.C.S. and MAHMOUD I. SEDIK, M.Sc.
}

The Department of Endocrine Surgery Unit, Faculty of Medicine, Ain Shams University

\begin{abstract}
Background: Thyroid cancer has the highest increase in incidence rate among all cancers, and this is largely but not full attributed to the increased detection of subclinical papillary carcinomas, the high incidence of occult nodal metastasis in PTC, advocating prophylactic central compartment neck dissection (pCCND) for the initial management of these tumors is, in theory, the ideal thing to do. Nevertheless, the role of pCCND in the management of PTC remains controversial regarding its benefits and risks.
\end{abstract}

Aim of Study: The aim of this study is to compare between total thyroidectomy with or without prophylactic central compartment neck dissection in case of papillary thyroid cancer with clinically negative cervical LN metastasis, focusing mainly on the rate of complications and the risk of recurrence of the disease.

Patients and Methods: This is a retrospective comparative study was conducted in the Department of Endocrine Surgery Unit, Ain Shams University hospitals and Shefa Elorman hospital, the study included 40 cases diagnosed with papillary thyroid cancer with clinical negative LNs, operated between March 2013 and March 2018.

Sampling Method: we collected 40 cases of papillary thyroid cancer with clinical negative LNs operated in the department of endocrine surgery unit, Ain Shams University hospitals and Shefa Elorman hospital, between March 2013 and March 2018, 20 of them (group 1) underwent total thyroidectomy and 20 cases (group 2) underwent total thyroidectomy and prophylactic central compartment neck dissection.

Results: Females to male ratio was 17:3 in both groups with no statistical significant difference $(p=1)$, the mean age of the participants in group (1) was $39.5 \pm 10.1$ years while in group (2) was $37.5 \pm 7.4$, with no statistical significant difference between both groups $(p=0.742)$, the mean operative time in group (1) patients was (122.1 $\pm 19.1 \mathrm{~min}$.) while in group (2) patients was (182.2 $\pm 15.3 \mathrm{~min}$.) with statistically significant relationship, only one case $5 \%$ in group (2) patients suffered hoarseness of voice.5\% of group (1) patients and $10 \%$ of group (2) patients suffered from transient hypocalcemia, one

Correspondence to: Dr. Ayman A. Abd-Rabhou,

The Department of Endocrine Surgery Unit,

Faculty of Medicine, Ain Shams University patient (5\%) in group (1) patients had recurrence and 4 patients (20\%) of group (2) patients suffered from recurrence.

Conclusion: Total thyroidectomy with prophylactic central LN dissection done in cases suffering from PTC with clinically negative cervical LNs increase operative time and postoperative hospital stay in comparison to total thyroidectomy with no statistical difference as regard to surgical complications and post-operative recurrence especially with presence of post-operative radioactive ablation.

Key Words: Papillary thyroid carcinoma - Prophylactic central compartment neck dissection - Total thyroidectomy.

\section{Introduction}

THYROID cancer has the highest increase in incidence rate among all cancers, and this is largely but not full attributed to the increased detection of subclinical papillary carcinomas [1]

As a result, the surgical strategy undertaken in the management of these tumors has been gaining increasing popularity among endocrinologists and endocrine surgeons. Papillary thyroid carcinomas (PTC) are considered favorable prognosis cancers. Most patients have a 5-year overall survival rate well above $90 \%$ [2].

Therefore, disease-free survival has replaced overall survival as the main outcome of interest when effective initial management of these tumors is evaluated.

Given the high incidence of occult nodal metastasis in PTC, advocating prophylactic central compartment neck dissection (pCCND) for the initial management of these tumors is, in theory, the ideal thing to do. Nevertheless, the role of pCCND in the management of PTC remains controversial regarding its benefits and risks [3]. 
Prophylactic neck dissection is defined as neck dissection in the absence of clinical evidence of nodal involvement whether on preoperative examination and imaging studies or during intraoperative evaluation. It is synonymous with elective/routine dissection [4].

Essential to any assessment of the role of pCC$\mathrm{ND}$ is to verify its oncologic rationale and whether its benefit outweighs its potential morbidity. Proposed potential benefits of pCCND include: Eliminating a potential source of recurrence subsequently avoiding potential morbidity of revision surgery, increasing the accuracy of disease staging for radioactive iodine (RAI) dosing and long-term follow-up, and improved accuracy of thyroglobulin surveillance [5].

While occult node positivity is quite common in PTC (even in subcentimetric cancers), it rarely demonstrates prognostic parameters of recurrence and/or a possibly worse disease-specific survival. Occult metastases usually tend to be small in size and number, with no extranodal extension, and a median risk of recurrence of only $2 \%$ [3] .

Moreover, the comparability in oncologic outcome between those who undergo pCCND and those who do not is a testimony to the indolent biologic behavior of subclinical nodal disease [6]

Further proof of the clinical stability of occult nodal disease, is the rare progression to locoregional recurrence among untreated patients.

Ywata de Carvalho et al. [7] or those who did not receive RAI adjuvant therapy [8].

A recent meta-analysis demonstrated that the presence of occult central nodal metastasis was not a significant predictor of recurrence nor did pCCND improve local control [9].

Reoperation for recurrent disease in the central neck, despite being uncommon, is challenging. However, in experienced hands the safety of CCND as a secondary operation was comparable to it as a primary one [10] .

One of the arguments for the use of pCCND is that it influences the usage of RAI through identifying the true nodal status of patients. Accordingly, patients may be stratified to receive higher doses of RAI or spared empiric postoperative RAI therapy [11].

The American joint committee on cancer (AJCC) tumor, nodal disease and distant metastasis (TNM) staging system considers nodal metastasis a prognostic factor for patients above the age of 45 years [12].

However, it does not differentiate between microscopic and macroscopic metastases that have different implications on outcome. Therefore, microscopic upstaging may lead to potentially unnecessary or additional treatments and reevaluations that are not devoid of adverse consequences [13].

On the other hand, giving empiric postoperative RAI based on the assumption of node positivity does not seem to be appropriate especially that the clinical stability of occult metastases in untreated patients or those who did not receive postoperative RAI has been demonstrated [14].

\section{Aim of the work:}

The aim of this study is to compare between total thyroidectomy with or without prophylactic central compartment neck dissection in case of papillary thyroid cancer with clinically negative cervical LN metastasis, focusing mainly on the rate of complications and the risk of recurrence of the disease.

\section{Subjects and Methods}

\section{Study group:}

This is a retrospective comparative study was conducted in the Department of Endocrine Surgery Unit, Ain Shams University Hospitals and Shefa Elorman hospital, the study included 40 cases diagnosed with papillary thyroid cancer with clinical negative LNs, operated between March 2013 and March 2018.

Sampling method: We collected 40 cases of papillary thyroid cancer with clinical negative LNs operated in the Department of Endocrine Surgery Unit, Ain Shams University Hospitals and Shefa Elorman hospital, between March 2013 and March 2018,20 of them (group 1) underwent total thyroidectomy and 20 cases (group 2) underwent total thyroidectomy and prophylactic central compartment neck dissection.

\section{Inclusion criteria were:}

Patients with early papillary thyroid cancer (T1, T2 N0 M0), previously diagnosed with FNAC or histopathological surprise in patients underwent total thyroidectomy.

\section{Exclusion criteria were:}

- Papillary thyroid tumor but unfit for operation.

- Papillary thyroid tumor associated with metastasis. 
- Papillary thyroid tumor associated with clinically positive cervical LNs (central or lateral).

- Recurrent papillary thyroid tumor.

- Papillary thyroid tumor and previous thyroid operation.

- Locally advanced papillary thyroid cancer (T3,T4).

- Micro papillary thyroid Cancer.

\section{Pre-operative work up:}

History was taken including age, sex, history of neck swelling, toxic symptoms (palpitation, weight loss, nervousness, heat intolerance, insomnia), pressure symptoms (dyspnea, dysphagia, stridor and hoarseness of voice) and cachexia.

Examination was done including generally regarding pulse, temperature, blood pressure, respiratory rate, pallor, cyanosis, jaundice, toxic signs (tremors, exophthalmos) and locally including inspection for thyroid swelling (size, shape, surface, extent, movement with deglutition and tongue protrusion), dilated neck veins, skin pigmentation and associated other neck swellings (enlarged lymph nodes), palpation for thyroid swelling (tenderness, temperature, size, extension, consistency, surface, edge, relation to skin, muscles and cervical lymph nodes status), percussion for assessment of retrosternal extension and auscultation to hear bruit in thyrotoxic cases.

Investigations was done including thyroid profile, neck ultrasound, Fine needle aspiration biopsy (FNAC). And thyroid scan if toxic goitre.

\section{Operative and post-operative data:}

In this study:

All cases underwent total thyroidectomy using almost same operative techniques whereas, starting with patient under general anasthesia with endotracheal intubation, in supine position with neck hyperextended and with table tilt 15 degree head up, transverse incision is done, two finger breadth above the sternal notch whereas, skin and platysma incised, both upper and lower flap are elevated then deep fascia vertically opened in the midline, strap muscles then retracted, pretracheal fascia vertically opened to expose thyroid gland, middle thyroid vein then ligated, superior pedicle dissected whereas, superior thyroid artery and vein individually ligated and divided at thyroid pole to avoid external laryngeal nerve injury, dissection done in avascular plane between cricothyroid and gland.

Both superior and inferior parathyroid glands identified and dissected and recurrent laryngeal nerve identified with careful dissection through its entire course whereas, inferior thyroid artery ligated at capsular level, then mobilized gland removed.

In group (2), cases underwent total thyroidectomy followed by central compartment neck dissection whereas, extending from hyoid bone above, brachiocephalic vein below and carotids on both sides, paratracheal, tracheoesophageal, pretracheal, prelaryngeal nodes removed.

Post-operative histopathological reports were collected to be assessed, operative data was collected as regard to operative time and post-operative hospital stay.

Operative complications were assessed throughout occurrence of hoarseness of voice, hypocalcemia symptoms (circumoral tingling, numbness, carpopedal spasm and laryngeal stridor) and postoperative hemorrhage.

\section{Follow-up strategy:}

Recurrence of disease during follow-up period was assessed by regular clinical examination every 3-6 months, serial thyroglobulins ( $\mathrm{Tg}$ ) and thyroglobulins anti-bodies (Tg Abs) and regular neck ultrasound assessments.

\section{Results}

We displayed the results of our study, which was carried out on 40 cases.

- Group $1=$ Total thyroidectomy.

- Group 2 = Total thyroidectomy plus prophylactic central $\mathrm{LN}$ dissection.

Table (1): Patient characteristics.

\begin{tabular}{cllc}
\hline & Group (1) & Group (2) & $p$-value \\
\hline Age: & & & \\
$\quad$ Mean (yr.) & $39.5 \pm 10.1$ & $\begin{array}{l}37.5 \pm 7.4 \\
(26-60)\end{array}$ & 0.742 \\
$\quad$ Range & $25-52$ & & \\
Gender: & & & \\
$\quad$ Male & $3(15 \%)$ & $3(15 \%)$ & 1.00 \\
$\quad$ Female & $17(85 \%)$ & $17(85 \%)$ & \\
Toxic status: & & & \\
$\quad$ Yes & $0(0 \%)$ & $0(0 \%)$ & \\
$\quad$ No & $20(100 \%)$ & $20(100 \%)$ & \\
\hline
\end{tabular}

Table (1):

- Females to male ratio was 17:3 in both groups with no statistical significant difference $(p=1)$, Fig. (1).

- There is female predominance in our study in both groups the female patients were $85 \%$.

- The mean age of the participants in group (1) was $39.5 \pm 10.1$ years while in group (2) was $37.5 \pm 7.4$, with no statistical significant difference between both groups ( $p=0.742)$, Fig. (2). 
- All patients in both groups did not show toxic status.

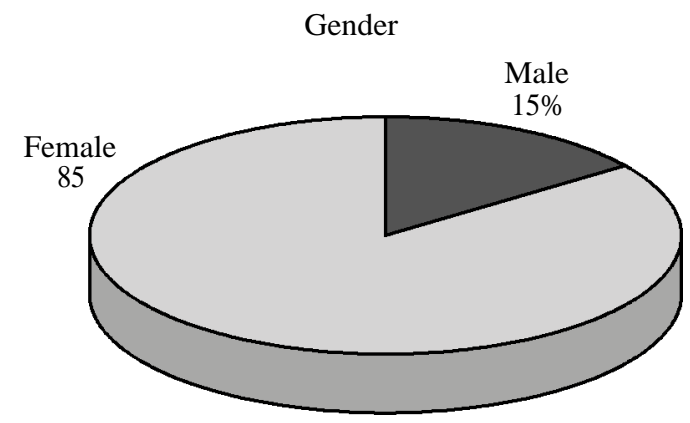

Fig. (1): Gender distribution among group (1).

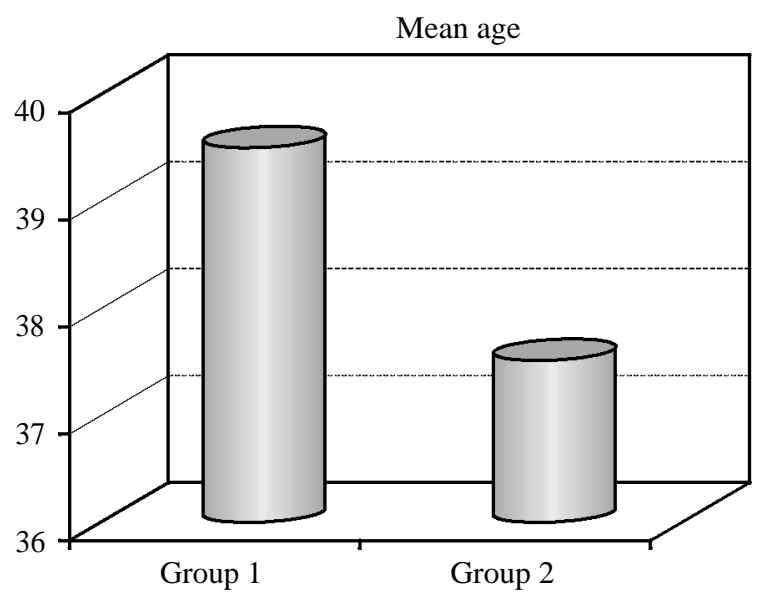

Fig. (2): Mean age of the studied group.

Table (2): Histopathological data.

\begin{tabular}{|c|c|c|c|}
\hline & Group (1) & Group (2) & $p$-value \\
\hline $\begin{array}{l}\text { Subtype: } \\
\text { Conventional } \\
\text { Others }\end{array}$ & $\begin{array}{l}19(95 \%) \\
1(5 \%) \\
\text { follicular }\end{array}$ & $\begin{array}{l}19(95 \%) \\
1(5 \%) \\
\text { follicular }\end{array}$ & 1.00 \\
\hline $\begin{array}{l}\text { Size }(\mathrm{cm} .) \text { : } \\
\text { Mean } \\
\text { Range }\end{array}$ & $\begin{array}{l}2.14 \pm .6 \\
1,2-3.3\end{array}$ & $\begin{array}{l}2.16 \pm .8 \\
1-4\end{array}$ & 0.917 \\
\hline $\begin{array}{l}\text { Multifocality: } \\
\text { Yes } \\
\text { No }\end{array}$ & $\begin{array}{l}3(15 \%) \\
17(85 \%)\end{array}$ & $\begin{array}{l}7(35 \%) \\
13(65 \%)\end{array}$ & 0.144 \\
\hline $\begin{array}{l}\text { Hashimoto's thyroiditis: } \\
\text { Yes } \\
\text { No }\end{array}$ & $\begin{array}{l}4(20 \%) \\
16(80 \%)\end{array}$ & $\begin{array}{l}8(40 \%) \\
12(60 \%)\end{array}$ & 0.168 \\
\hline $\begin{array}{l}\text { T Stage: } \\
\text { T } 1 \\
\text { T } 2\end{array}$ & $\begin{array}{l}12(60 \%) \\
8(40 \%)\end{array}$ & $\begin{array}{l}9(45 \%) \\
11(55 \%)\end{array}$ & 0.432 \\
\hline $\begin{array}{l}\text { Excised parathyroid gland. } \\
\text { Yes } \\
\text { No }\end{array}$ & $\begin{array}{l}1(5 \%) \\
19(95 \%)\end{array}$ & $\begin{array}{l}2(10 \%) \\
18(90 \%)\end{array}$ & 0.548 \\
\hline $\begin{array}{l}\text { No of dissected LNs: } \\
\text { Mean } \\
\text { Range }\end{array}$ & & $\begin{array}{l}6.3 \pm 2.1 \\
3-10\end{array}$ & \\
\hline $\begin{array}{l}\text { Cases with positive LNs: } \\
\text { No of positive LNs: } \\
\text { Mean } \\
\text { Range }\end{array}$ & & $\begin{array}{l}9(45 \%) \\
1.5 \pm 1.2 \\
0-3\end{array}$ & \\
\hline
\end{tabular}

Table (2): As regard the histopathological subtype, $95 \%$ of patients on both groups were conventional subtype with no statistical significant difference between both groups, Fig. (3).

Mean size of tumor in group (1) was $2.14 \mathrm{~cm}$. and for group (2), it was $2.16 \mathrm{~cm}$. with no statistical significant difference between both groups.

Multifocal disease was found in $15 \%$ of group (1) patients and 35\% of group (2) with no statistical significant difference between both groups.

Hashimoto thyroiditis was found in $20 \%$ of group (1) patients and $40 \%$ of group (2) patients with no statistical significant difference between both groups.

$60 \%$ of patients in group (1) and $45 \%$ of patients in group (2) presented with T1 stage with no statistical significant difference between both groups.

There was $5 \%$ of group (1) patients who showed inadvertently excised parathyroid gland and $10 \%$ of group (2) patients with no statistical significant difference between both groups.

The mean of NO. of dissected LNs is $(6.3 \pm 2.1)$, mean NO. of positive LNs is $(1.6 \pm 1.2)$ and NO. of cases with positive LNs was 9 cases, Fig. (4).

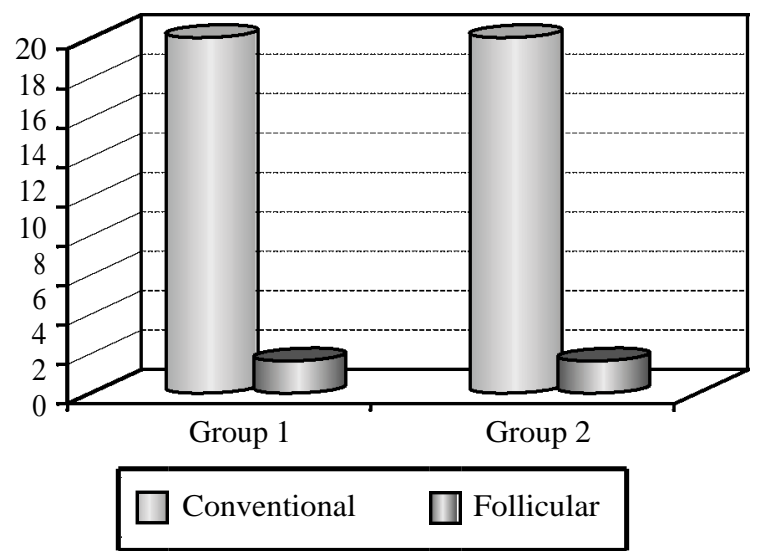

Fig. (3): Subtype of thyroid carcinoma in group (1) \& group (2).

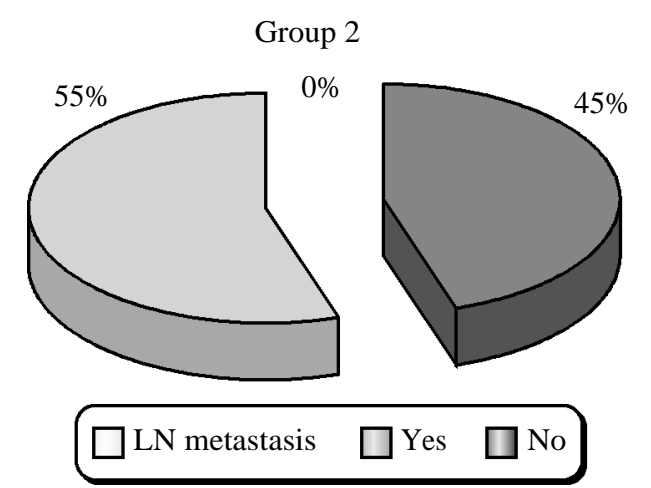

Fig. (4): Cases with positive LNs among group (2). 
Table (3): Operative and post-operative data.

\begin{tabular}{llll}
\hline & Group (1) & Group (2) & $p$-value \\
\hline $\begin{array}{l}\text { Operative time } \\
\text { (min.): } \\
\quad \text { Mean }\end{array}$ & & & \\
$\quad$ Range & $122.1 \pm 19.1$ & $182.2 \pm 15.3$ & $<0.001^{*}$ \\
$\begin{array}{l}\text { Duration of hospital } \\
\text { stay (days): }\end{array}$ & $90-150$ & $155-210$ & \\
$\quad$ Mean & & & \\
$\quad$ Range & $2.7 \pm 1.03$ & $4.6 \pm 1.1$ & $<0.001^{*}$ \\
$\begin{array}{l}\text { Hoarseness of voice: } \\
\text { No }\end{array}$ & $1-4$ & $2-7$ & \\
$\quad$ Yes & $20(100 \%)$ & $19(95 \%)$ & 0.311 \\
& 0 & $1(5 \%)$ & \\
Hypocalcemia: & & transient & \\
$\quad$ Yes & $1(5 \%)$ & $2(10 \%)$ & 0.548 \\
$\quad$ No & transient & transient & \\
$\quad 19(95 \%)$ & $18(90 \%)$ & \\
$\begin{array}{l}\text { Post-operative } \\
\text { Hemorrhage: }\end{array}$ & & & \\
$\quad$ Yes & & & \\
$\quad$ No & 0 & $1(5 \%)$ & 0.311 \\
\hline
\end{tabular}

The mean operative time in group (1) patients was (122.1 $\pm 19.1 \mathrm{~min}$.) while in group (2) patients was $(182.2 \pm 15.3 \mathrm{~min}$.) with statistically significant relationship, Fig. (5).

The mean hospital stay in days, it was (2.7 \pm 1.03 days) in group (1) and (4.6 \pm 1.1 days) in group (2), with statistically significant relationship.

Only one case in group (2) patients suffered hoarseness of voice.

$5 \%$ of group (1) patients and $10 \%$ of group (2) patients suffered from transient hypocalcemia.

Only one case in group (2) patients suffered from post-operative hemorrhage.

There is no statistical significance relationship between both groups as regard to hoarseness of voice, hypocalcemia and post-operative hemorrhage.

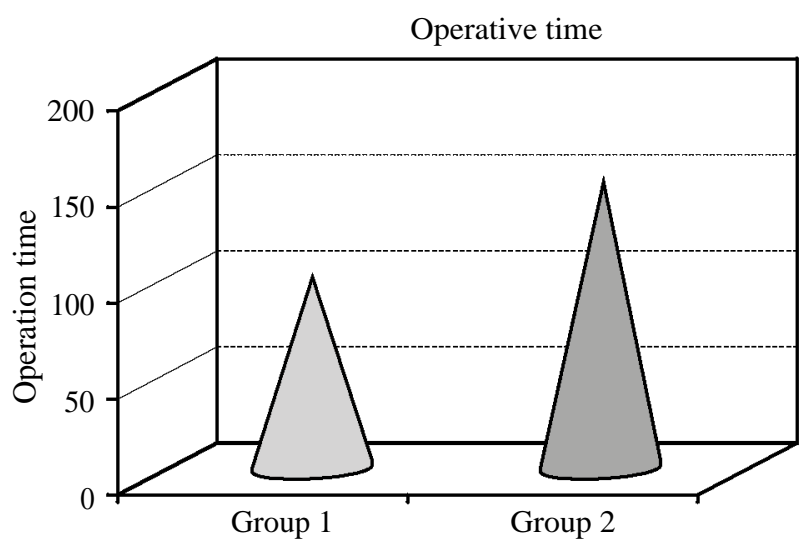

Fig. (5): Mean operative time for group (1) and group (2).
Table (4): Data of recurrence.

\begin{tabular}{llll}
\hline & Group (1) & Group (2) & $p$-value \\
\hline Recurrence: & & & \\
$\quad$ Yes & $1(5 \%)$ & $4(20 \%)$ & 0.151 \\
$\quad$ No & $19(95 \%)$ & $16(80 \%)$ & \\
Site of recurrence: & & & \\
$\quad$ Central zone level (VI) & 0 & 0 & 0.151 \\
$\quad$ Lateral zone level (II) & 0 & 0 & \\
$\quad$ Lateral zone level (III) & 0 & 2 & \\
$\quad$ Lateral zone level (IV) & 1 & 2 & \\
$\quad$ Distant metastasis & 0 & 0 & \\
Side of recurrence: & & & \\
$\quad$ Ipsilateral & $1(5 \%)$ & $3(15 \%)$ & 0.323 \\
Bilateral & 0 & $1(5 \%)$ & \\
\hline
\end{tabular}

One patient (5\%) in group (1) patients had ipsilateral level (IV) recurrence and 4 patients $(20 \%)$ of group (2) patients suffered from recurrence ( 2 of them had ipsilateral level (III), one patient had ipsilateral level (IV) and one patient had bilateral level (IV) recurrence). This difference in recurrence was statistically insignificant between both groups, Figs. $(6,7)$.

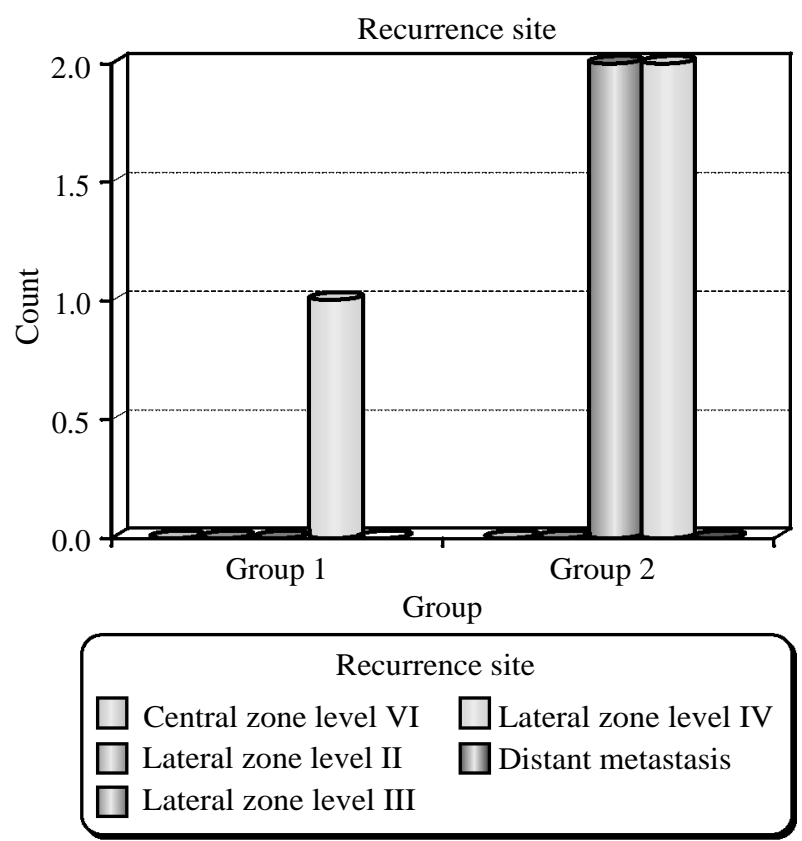

Fig. (6): Recurrence site.

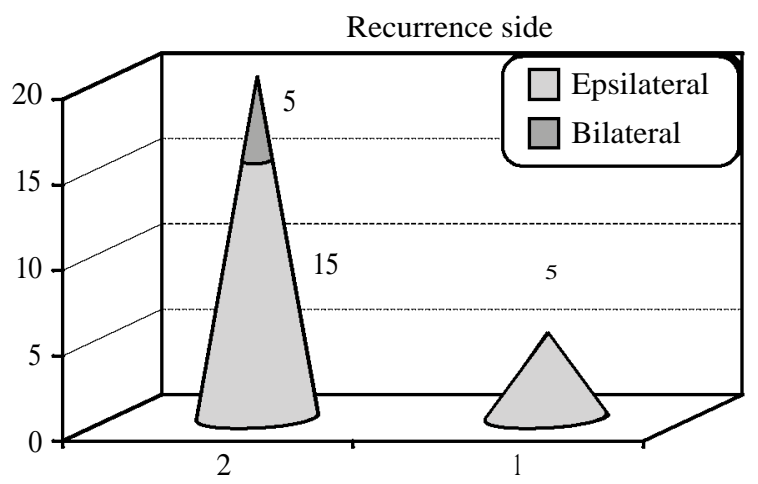

Fig. (7): Recurrence side. 


\section{Discussion}

Papillary thyroid carcinoma is the most common type of thyroid cancer, representing 75 percent to 85 percent of all thyroid cancer cases. It occurs more frequently in women and presents in the (2055) year age group [15]

It is also the predominant cancer type in children with thyroid cancer, and in patients with thyroid cancer who have had previous radiation to the head and neck. It is often well-differentiated, slowgrowing, and localized, although it can metastasize [16]

FNA accuracy is very high and it is a process widely used in these cases. Other investigation methods include ultrasound imaging and nuclear scan. The ultrasound is a useful test to distinguish solid from cystic lesions and to identify calcifications. The thyroid ultrasound is also very effective to discover microcarcinomas, which refer to very small carcinomas $(<1 \mathrm{~cm})$ [17]

Surgery remains the mainstay of treatment for papillary thyroid cancer. The Revised 2009 American Thyroid Association guidelines for papillary thyroid cancer state that the initial procedure should be near-total or total thyroidectomy. Thyroid lobectomy alone may be sufficient treatment for small $(<1 \mathrm{~cm})$, low-risk, unifocal, intrathyroidal papillary carcinomas in the absence of prior head and neck irradiation or radiologically or clinically involved cervical nodal metastasis [18].

The aim of this study is to compare total thyroidectomy with or without prophylactic central compartment neck dissection, focusing mainly on the rate of complications and the risk of recurrence of the disease.

In this study, 40 patients were included and they were divided into 2 groups. Group (1) patients were treated with total thyroidectomy while group (2) patients were treated with total thyroidectomy plus prophylactic central $\mathrm{LN}$ dissection.

As regard to demographic data of the current study, the mean age of group (1) patients was $(39.5 \pm 10.1)$ years and the mean age of group (2) patients was $(37.5 \pm 7.4)$ years, while in Lim et al. [19] the mean age of group (1) patients was (39.5 \pm 5.3 ) years and the mean age of group (2) patients was (37.2 \pm 3 ) years, but in Kuo et al. [20] the mean age of papillary carcinoma patients was $(48.8 \pm 15.7)$ years.

Speaking about sex distribution in this study, 6 cases $(15 \%)$ were males and 34 cases $(85 \%)$ were females in both groups, so as in Yildiz et al. [22] who found that the incidence of thyroid cancer was $(17 \%)$ in males and $(83 \%)$ in females. There is no statistical difference between both groups as regard to age and gender.

Thyroid cancer is 2.9-times more common in women than men. The less aggressive histologic subtypes of thyroid cancer are more common in women, whereas the more aggressive histologic subtypes have similar gender distribution [21].

As regard to histological subtype in our study, 38 cases $(95 \%)$ of the patients had conventional papillary thyroid cancer while 2 cases $(5 \%)$ of patients had follicular subtype of papillary thyroid cancer in both groups, while in Lim et al. [19] (94.3\%) of the patients had conventional papillary thyroid cancer, while $(5.7 \%)$ of patients had follicular subtype of papillary thyroid cancer.

In our study, the mean tumor size of group (1) patients was $(2.14 \pm .6) \mathrm{cm}$. and the mean tumor size of group (2) patients was $(2.16 \pm .8) \mathrm{cm}$., while in Durante et al. [23] the mean tumor size of papillary thyroid cancer patients was $(1.7 \pm 0.4) \mathrm{cm}$. also, in Al Afif et al. [24] the mean tumor size of papillary thyroid cancer patients was $(2.2) \mathrm{cm}$.

In this study, 3 cases (15\%) had multifocal Papillary thyroid cancer in group (1) patients and in group (2) patient, it was 7 cases (35\%), while in Kiratli et al. [25] (20\%) of the patients had multifocal Papillary thyroid cancer and in Durante et al. [23] (35.7\%) of the patients had multifocal Papillary thyroid cancer.

Papillary thyroid cancer often presents with multifocal tumors, taken together, multifocality was associated with more aggressive and poorer prognosis. Capsular invasion, advanced pathological $\mathrm{T}$ classification and $\mathrm{N}+$ stage were independent predictors of multifocal PTC. Total thyroidectomy with prophylactic bilateral central lymph node dissection should be recommended during surgery in multifocal PTC due to a higher propensity for level VI lymph node metastasis [26].

As regard to Hashimoto's thyroiditis, 4 cases (20\%) of group (1) patients and 8 cases $(40 \%)$ of group (2) patients had Hashimoto's thyroiditis.

In Mazokopakis et al. [27] who found that the prevalence of Hashimoto's thyroiditis in papillary carcinoma patients were $28.57 \%$, also Kurukahvecioglu et al. [28] found that the prevalence of Hashimoto's thyroiditis in papillary carcinoma patients were $36.66 \%$. 
In this study, there were 12 cases $(60 \%)$ in group (1) patients and 9 cases (45\%) of group (2) patients had T 1 stage, while 8 cases (40\%) in group (1) patients and 11 case (55\%) of group (2) patients had T2 stage.

In a study done by Choi et al. [29] who found that $43.7 \%$ of papillary thyroid patients were $\mathrm{T} 1$ stage and $1.1 \%$ had $\mathrm{T} 2$ stage.

Also, Grogan et al. [30] who found that $46 \%$ of papillary thyroid patients were T1 stage and 19\% had T2 stage. While found that $43.5 \%$ of papillary thyroid patients were $\mathrm{T} 1$ stage and $13 \%$ had T2 stage.

In this study, in group (2) patients who underwent total thyroidectomy with prophylactic central LN dissection, histopathological examination revealed that the No. of dissected LNs ranged from 3-10 nodes with mean $(6.3 \pm 2.1)$ nodes and the range of positive LNs was from 0-3 nodes with mean (1.6 \pm 1.2$)$ nodes and total cases with pathologically positive $\mathrm{LNs}(\mathrm{PN}+)$ were 9 cases $(45 \%)$ of group (2) patients.

In Robinson et al. [31], (47.4\%) of thyroid cancer patients had node-positive disease and in Onkendi et al. [32] (40\%) of thyroid cancer patients had node-positive disease, and Grogan et al. [30] $42 \%$ of papillary thyroid cancer patients had node positive disease, also in Matsuzu et al. [33], the mean of the dissected lymph node in central compartment in papillary thyroid cancer patients was $(5.5 \pm 1.7)$. and in Kutler et al. [34] the mean of the dissected lymph node in central compartment in papillary thyroid cancer patients was (5.7).

Lymph nodes (LNs) represent the most common site of persistent, recurrent, and/or progressive disease. Surgical resection is the mainstay of treatment; however, the adequacy of the number of LNs resected and examined at the time of surgery has not been determined and remains a controversial issue [31].

In this study, one case (5\%) of group (1) patients and 2 cases (10\%) of group (2) patients had inadvertant parathyroidectomy, while in Chrisoulidou et al. [35] incidental parathyroidectomy in thyroid cancer patients was $(11.5 \%)$.

Parathyroidectomy during total thyroidectomy with central neck dissection for papillary thyroid carcinoma is common and involves the inferior glands more frequently in patients with extended resections and clinical N1a disease. Inadvertent resection of parathyroid glands is associated with greater rates of postoperative hypocalcemia and permanent hypoparathyroidism [36].

There is no statistical difference in histopathological data between both groups as regard to histopathological subtype, tumor size, multifocality, Hashimoto's thyroiditis, T stage and inadvertent excised parathryroid gland.

As regard to group (1) patients, total thyroidectomy operation was performed and the mean operative time was $(122.1 \pm 19.1)$ min., while in Bakkar et al. [37] the mean operative time was (122士 10.31) min.

In group (2) patients, total thyroidectomy and prophylactic central LN dissection operation was performed and the mean operative time was (182.2 \pm 15.3) min., while in Lecerf et al. [38] the mean operative time was $(180 \pm 8.63) \mathrm{min}$.

The mean duration of the hospital stay in group (1) patients was (2.7 \pm 1.03$)$ days, but in Kurukahvecioglu et al. [28] the mean hospital stay after total thyroidectomy was $(2.90 \pm 0.915)$ days.

The mean duration of the hospital stay in group (2) patients was (4.6 \pm 1.1$)$ days, while in Kwak et al. [39] the mean hospital stay after total thyroidectomy and central LN dissection operation was $(4.98 \pm 0.15)$ days.

There is statistical difference between both groups in operative time and hospital stay.

In group (1), there was no cases suffered from post-operative hoarseness of voice, while one case (5\%)of group (2) patients suffered from postoperative hoarseness of voice as in Aluffi et al. [40] $6.5 \%$ of the patients had hoarseness of voice after total thyroidectomy and central LN dissection.

One case $(5 \%)$ of group (1) patients suffered from post-operative transient hypocalcemia and 2 cases $(10 \%)$ in group (2) patients, while in Karamanakos et al. [41] $6.3 \%$ of the patients had postoperative hypocalcemia and in Seo et al. [42] 12.3\% of the patients had post-operative hypocalcemia.

Thyroid surgeries are among the most common operations performed in the world. Hypocalcemia following total thyroidectomy is a common complication that is sometimes difficult to correct. Temporary hypocalcemia occurs in $50-68 \%$ of post-TT patients, while permanent hypocalcemia occurs in 3\% of post-TT patients. Temporary hypocalcemia is defined by various authors as a postsurgery decrease in calcium $(\mathrm{Ca})$, lasting for 6 to 12 months; permanent hypocalcemia is a post-TT 
decrease in Ca lasting for more than 12 months [43].

In our study, there was no cases suffered from post-operative hemorrhage in group (1) patients, while one case (5\%) in group (2) suffered from post-operative hemorrhage.

None of the total thyroidectomy patients had post-operative hemorrhage in Duclos et al. [44], while in Efremidou et al. [45] $0.2 \%$ had postoperative hemorrhage.

There is no statistical difference between both groups as regard to post-operative complications including hoarseness of voice, hypocalcemia and post-operative hemorrhage.

In our study, one patient (5\%) in group (1) patients had ipsilateral level (IV) recurrence and 4 patients (20\%) of group (2) suffered from recurrence ( 2 of them had ipsilateral level (III), one patient had ipsilateral level (IV) and one patient had bilateral level (IV) recurrence. There is no statistical difference between both groups regarding post-operative recurrence.

In Roh et al. [46] loco regional recurrence after total thyroidectomy operation was $(4.1 \%)$, while in Zuniga and Sanabria [47] loco regional recurrence after total thyroidectomy and prophylactic central neck dissection was $(20.0 \%)$.

In Kruijff et al. [48] the recurrence after total thyroidectomy operation was $18 \%$ in level (III), and $18 \%$ in level (IV).

In Ahn et al. [49] the recurrence rate was highest at level (IV) (13/291, 4.5\%), followed by level (III) $(8 / 291,2.7 \%)$ and level (VI) $(7 / 291,2.4 \%)$ in the total thyroidectomy alone group. In the total thyroidectomy with central neck dissection group, level (IV) $(10 / 70,14.3 \%)$ was again most commonly involved in recurrence, followed by level (VI) $(4 / 70,5.8 \%)$ and level (III) $(3 / 70,4.3 \%)$.

Papillary thyroid carcinoma (PTC) has excellent survival, however, recurrence remains a major concern with up to $20 \%$ of patients developing recurrent disease at some point during their lifetime [50].

\section{Conclusion:}

In this study, we concluded that: Papillary thyroid carcinoma is the most common type of thyroid cancer and the main route of metastasis is lymph nodes to central LNs group. The mainstay of treatment is total thyroidectomy.
As regard cases suffering from PTC with clinically negative cervical LNs, total thyroidectomy with prophylactic central LN dissection (although no significant difference in complications) but increase operative time and post-operative hospital stay in comparison to total thyroidectomy without prophylactic central LN dissection with no statistical difference as regard to post-operative recurrence especially with presence of post-operative radioactive ablation.

\section{References}

1- MORRIS L. and MYSSIOREK D.: "Improved detection does not fully explain the rising incidence of welldifferentiated thyroid cancer: A population-based analysis", Am. J. Surg., 200 (4): 454-461, 2010.

2- GYORKI D.E., UNTCH B., TUTTLE R.M. and SHAHA A.R.: Prophylactic central neck dissection in differentiated thyroid cancer: An assessment of the evidence. Annals of Surgical Oncology, 20 (7): 2285-2289, 2013.

3- BARDET S., CIAPPUCCINI R., QUAK E., RAME J.P., BLANCHARD D., de RAUCOURT D. and HEUTTE N.: Prognostic value of microscopic lymph node involvement in patients with papillary thyroid cancer. The Journal of Clinical Endocrinology \& Metabolism, 100 (1): 132-140, 2015.

4- HARTL D.M., MAMELLE E., BORGET I., LEBOULLEUX S., MIRGHANI H. and SCHLUMBERGER M.: Influence of prophylactic neck dissection on rate of retreatment for papillary thyroid carcinoma. World journal of surgery, 37 (8): 1951-1958, 2013.

5- BARCZYN 'SKI M., KONTUREK A., STOPA M. and NOWAK W.: Prophylactic central neck dissection for papillary thyroid cancer. British Journal of Surgery, 100 (3), 410-418, 2013.

6- VIOLA D., MATERAZZI G., VALERIO L., MOLINARO E., AGATE L., FAVIANA P. and MICCOLI P.: Prophylactic central compartment lymph node dissection in papillary thyroid carcinoma: Clinical implications derived from the first prospective randomized controlled single institution study. The Journal of Clinical Endocrinology \& Metabolism, 100 (4): 1316-1324, 2015.

7- YWATA de CARVALHO A., CHULAM T.C. and KOWALSKI L.P.: "Long-term results of observation vs. prophylactic selective level VI neck dissection for papillary thyroid carcinoma at a cancer center", JAMA Otolaryngol. Head Neck Surg., 141 (7): 599-606, 2015.

8- LIU J., XU Z., LI Z., ZHANG Z., TANG P. and LIU S. Long-term outcomes of observation for clinically negative central compartment lymph nodes in papillary thyroid carcinoma. European Archives of Oto-Rhino-Laryngology, 272 (12): 3801-3804, 2015.

9- QU N., ZHANG L., JI Q.H., CHEN J.Y., ZHU Y.X., et al.: "Risk factors for central compartment lymph node metastasis in papillary thyroid microcarcinoma: A metaanalysis", World J. Surg., 39 (10): 2459-2470, 2015.

10- SHEN W.T., OGAWA L., RUAN D., SUH I., KEBEBEW E., DUH Q.Y. and CLARK O.H.: Central neck lymph node dissection for papillary thyroid cancer: Comparison 
of complication and recurrence rates in 295 initial dissections and reoperations. Archives of Surgery, 145 (3): 272$275,2010$.

11- RUEL E., THOMAS S., DINAN M.A., PERKINS J.M., ROMAN S.A. and SOSA J.A.: Knowledge of pathologically versus clinically negative lymph nodes is associated with reduced use of radioactive iodine post-thyroidectomy for low-risk papillary thyroid cancer. Endocrine, 52 (3): 579-586, 2016.

12- EDGE S.B. and COMPTON C.C.: "AJCC Cancer Staging Manual, 7 th edition", Ann. Surg. Oncol., 17 (6): 1471 $1474,2010$.

13- CLEMENT S.C., PEETERS R.P., RONCKERS C.M., LINKS T.P., VAN DEN HEUVEL-EIBRINK M.M., VAN DIJKUM E.N. and VAN SANTEN, H. M.: Intermediate and long-term adverse effects of radioiodine therapy for differentiated thyroid carcinoma-a systematic review. Cancer treatment reviews, 41 (10): 925-934, 2015.

14- ITO Y., MIYAUCHI A., INOUE H., FUKUSHIMA M., KIHARA M., et al.: "An observational trial for papillary thyroid microcarcinoma in Japanese patients", World J. Surg., 34 (1): 28-35, 2010.

15- PELlEGRITI G., FRASCA F., REGALBUTO C., SQUATRITO S. and VIGNERI R.: Worldwide increasing incidence of thyroid cancer: Update on epidemiology and risk factors. Journal of Cancer Epidemiology, 2013.

16- GRUBER J.J. and COLEVAS A.D.: Differentiated thyroid cancer: Focus on emerging treatments for radioactive iodine-refractory patients. The oncologist, 20 (2): 113, 2015.

17- USTUN B., CHHIENG D., PRASAD M.L., HOLT E., HAMMERS L., CARLING T. and ADENIRAN A.J.: Follicular variant of papillary thyroid carcinoma: Accuracy of FNA diagnosis and implications for patient management. Endocrine Pathology, 25 (3): 257-264, 2014.

18- JAYARANGAIAH A., SIDHU G., BROWN J., BARRETT-CAMPBELL O., BAHTIYAR G., YOUSSEF I. and McFARLANE S.I.: Therapeutic options for advanced thyroid cancer. International journal of clinical endocrinology and metabolism, 5 (1): 26, 2019.

19- LIM S.T., JEON Y.W. and SUH Y.J.: The prognostic values of preoperative tumor volume and tumor diameter in T1N0 papillary thyroid cancer. Cancer research and treatment: Official journal of Korean Cancer Association, 49 (4): 890, 2017.

20- KUO S.F., CHAO T.C., CHANG H.Y., HSUEH C., LIN C.L., CHIANG K.C. and LIN J.D.: Prognosis of papillary thyroid cancers with positive serum thyroglobulin antibody after total thyroidectomy. Asian Journal of Surgery, 40 (3): 186-192, 2017.

21- RAHBARI R., ZHANG L. and KEBEBEW E.: Thyroid cancer gender disparity. Future Oncology, 6 (11): 1771$1779,2010$.

22- YILDIZ S.Y., BERKEM H., YUKSEL B.C., OZEL H., KENDIRCI $M$. and HENGIRMEN S.: The rising trend of papillary carcinoma in thyroidectomies: 14-years of experience in a referral center of Turkey. World Journal of Surgical Oncology, 12 (1): 1-6, 2014.

23- DURANTE C., TOGNINI S., MONTESANO T., ORLANDI F., TORLONTANO M., PUXEDDU E. and PTC Study
Group: Clinical aggressiveness and long-term outcome in patients with papillary thyroid cancer and circulating anti-thyroglobulin autoantibodies. Thyroid, 24 (7): 1139 $1145,2014$.

24- AL AFIF A., WILLIAMS B.A., RIGBY M.H., BULLOCK M.J., TAYLOR S.M., TRITES J. and HART R.D.: Multifocal papillary thyroid cancer increases the risk of central lymph node metastasis. Thyroid, 25 (9): 1008-1012, 2015.

25- KIRATLI P.Ö., VOLKAN-SALANCI B., GÜNAY E.C., VARAN A., AKYÜZ C. and BÜYÜKPAMUKÇU M.: Thyroid cancer in pediatric age group: An institutional experience and review of the literature. Journal of pediatric hematology/oncology, 35 (2): 93-97, 2013.

26- GENPENG L., JIANYONG L., JIAYING Y., KE J., ZHIHUI L., RIXIANG G. and JINGQIANG Z.: Independent predictors and lymph node metastasis characteristics of multifocal papillary thyroid cancer. Medicine, 97 (5), 2018.

27- MAZOKOPAKIS E.E., TZORTZINIS A.A., DALIERAKIOTT E.I., TSARTSALIS A.N., SYROS P.K., KAREFILAKIS C.M. and STARAKIS I.K.: Coexistence of Hashimoto's thyroiditis with papillary thyroid carcinoma. A retrospective study. Hormones, 9 (4): 312-317, 2010.

28- KURUKAHVECIOGLU O.S.M.A.N., KARAMERCAN A.H.M.E.T., AKIN M.U.R.A.T., TEZEL E., EGE B., TANERI F.E.R.I.T. and ONUK E.: Potential benefit of oral calcium/vitamin D administration for prevention of symptomatic hypocalcemia after total thyroidectomy. Endocrine Regulations, 41 (1): 35-39, 2007.

29- CHOI J.S., CHUNG W.Y., KWAK J.Y., MOON H.J., KIM M.J. and KIM E.K.: Staging of papillary thyroid carcinoma with ultrasonography: performance in a large series. Annals of Surgical Oncology, 18 (13): 3572-3578, 2011.

30- GROGAN R.H., KAPLAN S.P., CAO H., WEISS R.E., DeGROOT L.J., SIMON C.A. and SCHECHTER R.B.: A study of recurrence and death from papillary thyroid cancer with 27 years of median follow-up. Surgery, 154 (6): 1436-1447, 2013.

31- ROBINSON T.J., THOMAS S., DINAN M.A., ROMAN S., SOSA J.A. and HYSLOP T.: How many lymph nodes are enough? Assessing the adequacy of lymph node yield for papillary thyroid cancer. Journal of Clinical Oncology, 34 (28): 3434, 2016.

32- ONKENDI E.O., McKENZIE T.J., RICHARDS M.L., FARLEY D.R., THOMPSON G.B., KASPERBAUER J.L. and GRANT C.S.: Reoperative experience with papillary thyroid cancer. World Journal of Surgery, 38 (3): 645-652, 2014.

33- MATSUZU K., SUGINO K., MASUDO K., NAGAHAMA M., KITAGAWA W., SHIBUYA H. and ITO K.: Thyroid lobectomy for papillary thyroid cancer: Longterm follow-up study of 1,088 cases. World Journal of Surgery, 38 (1): 68-79, 2014.

34- KUTLER D.I., CRUMMEY A.D. and KUHEL W.I.: Routine central compartment lymph node dissection for patients with papillary thyroid carcinoma. Head \& Neck, 34 (2): 260-263, 2012.

35- CHRISOULIDOU A., MANDANAS S., MITSAKIS P., ILIADOU P.K., MANAFIS K., FLARIS N. and PAZAITOU-PANAYIOTOU K.: Parathyroid involvement in 
thyroid cancer: An unforeseen event. World Journal of Surgical Oncology, 10 (1): 1-5, 2012.

36- FRIDMAN M., KRASKO O., BRANOVAN D.I., DABRYIAN S., PISARENKO A., LO C.Y. and LAM A.K.Y.: Factors affecting the approaches and complications of surgery in childhood papillary thyroid carcinomas. European Journal of Surgical Oncology, 45 (11): 2078-2085, 2019.

37- BAKKAR S., AL HYARI M., NAGHAWI M., CORSINI C. and MICCOLI P.: Transoral thyroidectomy: A viable surgical option with unprecedented complications-a case series. Journal of endocrinological investigation, 41 (7): 809-813, 2018.

38- LECERF P., ORRY D., PERRODEAU E., LHOMMET C., CHARRETIER C., MOR C. and de CALAN L.: Parathyroid hormone decline 4 hours after total thyroidectomy accurately predicts hypocalcemia. Surgery, 152 (5): 863 868,2012

39- KWAK H.Y., CHAE B.J., PARK Y.G., KIM S.H., CHANG E.Y., KIM E.J. and BAE J.S.: Comparison of surgical outcomes between papillary thyroid cancer patients treated with the Harmonic ACE scalpel and LigaSure Precise instrument during conventional thyroidectomy: A singleblind prospective randomized controlled trial. Journal of Surgical Research, 187 (2): 484-489, 2014.

40- ALUFFI P., POLICARPO M., CHEROVAC C., OLINA M., DOSDEGANI R. and PIA F.: Post-thyroidectomy superior laryngeal nerve injury. European Archives of Oto-Rhino-Laryngology, 258 (9): 451-454, 2001.

41- KARAMANAKOS S.N., MARKOU K.B., PANAGOPOULOS K., KARAVIAS D., VAGIANOS C.E., SCOPA C.D. and VAGENAS K.: Complications and risk factors related to the extent of surgery in thyroidectomy. Results from 2,043 procedures. Hormones, 9 (4): 318 $325,2010$.

42- SEO S.T., CHANG J.W., JIN J., LIM Y.C., RHA K.S. and KOO B.S.: Transient and permanent hypocalcemia after total thyroidectomy: Early predictive factors and long-term follow-up results. Surgery, 158 (6): 1492-1499, 2015.

43- EISMONTAS V., SLEPAVICIUS A., JANUSONIS V., ZEROMSKAS P., BEISA V., STRUPAS K. and MARTINKENAS A.: Predictors of postoperative hypocalcemia occurring after a total thyroidectomy: Results of prospective multicenter study. BMC Surgery, 18 (1): 1-12, 2018.

44- DUCLOS A., PEIX J.L., COLIN C., KRAIMPS J.L., MENEGAUX F., PATTOU F. and LIFANTE J.C.: Influence of experience on performance of individual surgeons in thyroid surgery: Prospective cross sectional multicentre study. BMJ, 344, 2012.

45- EFREMIDOU E.I., PAPAGEORGIOU M.S., LIRATZOPOULOS N. and MANOLAS K.J.: The efficacy and safety of total thyroidectomy in the management of benign thyroid disease: A review of 932 cases. Canadian Journal of Surgery, 52 (1): 39, 2009.

46- ROH J.L., PARK J.Y. and PARK C.I.: Total thyroidectomy plus neck dissection in differentiated papillary thyroid carcinoma patients: Pattern of nodal metastasis, morbidity, recurrence, and postoperative levels of serum parathyroid hormone. Annals of Surgery, 245 (4): 604, 2007.

47- ZUNIGA S. and SANABRIA A.: Prophylactic central neck dissection in stage N0 papillary thyroid carcinoma. Archives of Otolaryngology-Head \& Neck Surgery, 135 (11): 1087-1091, 2009.

48- KRUIJFF S., PETERSEN J.F., CHEN P., ANISS A.M., CLIFTON-BLIGH R.J., SIDHU S.B. and SYWAK M.S.: Patterns of structural recurrence in papillary thyroid cancer. World Journal of Surgery, 38 (3): 653-659, 2014.

49- AHN D., SOHN J.H. and PARK J.Y.: Surgical complications and recurrence after central neck dissection in $\mathrm{cN} 0$ papillary thyroid carcinoma. Auris Nasus Larynx, 41 (1): 63-68, 2014.

50- BATES M.F., LAMAS M.R., RANDLE R.W., LONG K.L., PITT S.C., SCHNEIDER D.F. and SIPPEL R.S.: Back so soon? Is early recurrence of papillary thyroid cancer really just persistent disease?. Surgery, 163 (1): 118-123, 2018. 


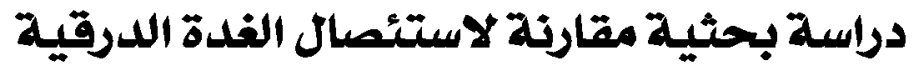

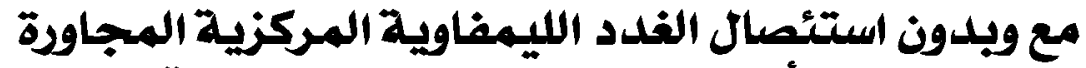

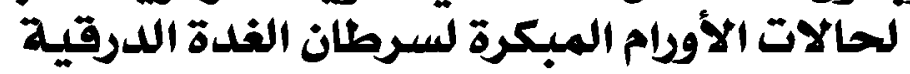

الخلفية: العلاج الجراحى في سرطان الغدة الارقية الحليمى يشمل استئصال الغدة الدرقية الكلى، وفى حالات الصابة الغدة الليمفاوية،

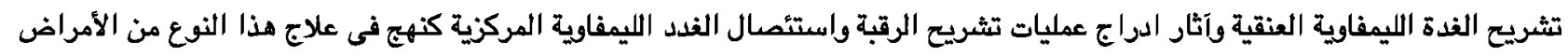



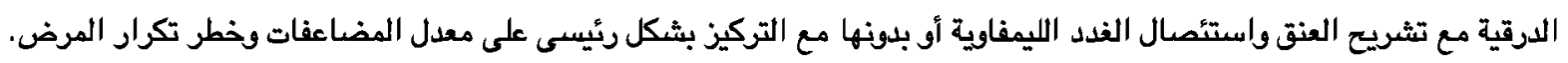

الهدف من الدراسدة: المقارنة بين استئصال الغدة الدرقية الكلى مع أو بلون تشريع الحيز المركزى الوقائى اللرقبة مع التركيز بشكل

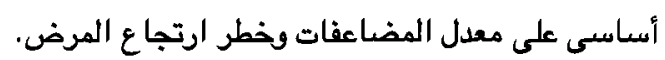

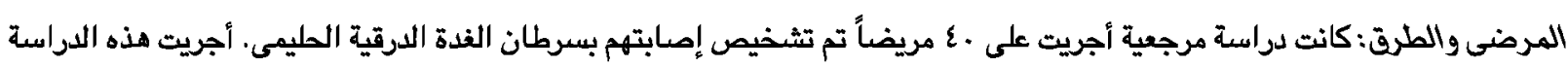

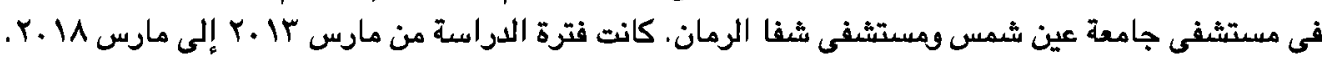

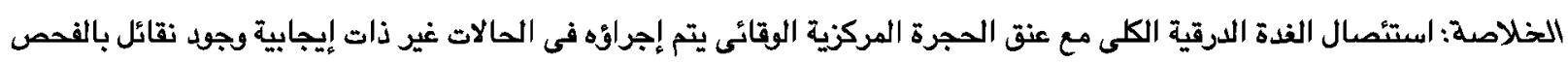

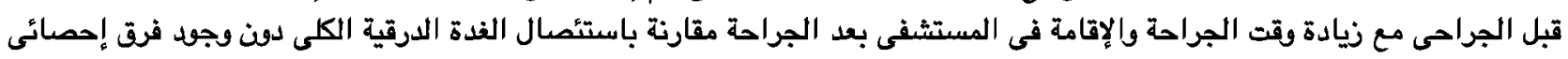

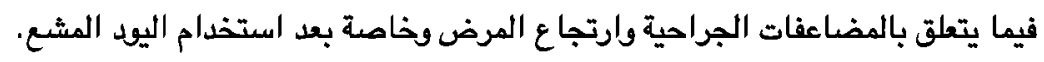

